\title{
iAl mirarte de Playa Ancha, lindo puerto! Edificación en altura, renta de suelo y extractivismo urbano en Valparaíso $(1991-2017)^{1}$
}

\section{Looking at you from Playa Ancha, beautiful port! Hige-rise building, land rent and urban extractivism in Valparaíso} $(1991-2017)^{2}$

\section{Carlos Vergara-Constela ${ }^{3}$ (1) y Nelson Carroza Athens ${ }^{4}$ (1)}

\begin{abstract}
RESUMEN
En este trabajo, se presentan resultados de investigación relativos a la edificación en altura en la comuna de Valparaíso. Mediante ellos, se muestra la superficie construida, su cantidad, localización y las rentas obtenidas de acuerdo con las temporalidades y los espacios de la ciudad (cerros y plan). Con ello, se plantea que esta forma de producción habitacional es propia de lógicas extractivistas y se vincula con modificaciones introducidas en los instrumentos de planificación urbana. Consecuentemente, los resultados expuestos permiten reconocer tres ciclos en la producción de edificaciones en altura en Valparaíso: albores (1996-2001), intensificación (2002-2010) y consolidación (2011-2017). En conjunto, estos ciclos dan cuenta de la diversidad de estrategias de la producción inmobiliaria que se observan en la ciudad. Asimismo, se establece que la renta promedio obtenida por las compañías inmobiliarias triplica la capitalización de quienes capturan renta vendiéndoles el suelo.
\end{abstract}

Palabras clave: desarrollo inmobiliario, vivienda, planificación urbana, geografía urbana.

\begin{abstract}
In this article, research results related to high-rise buildings in the Valparaiso district are presented. The built area, its quantity, location and the income obtained according to the temporalities and spaces of the city (hills and downtown) are shown in the findings. It is proposed that this form of housing production is typical of extractivist logics and is linked to modifications made in urban planning instruments. Consequently, the results presented allow us to recognize three cycles in the production of high-rise buildings in Valparaíso: beginning (1996-2001), intensification (2002-2010) and consolidation (2011-2017). Together, these cycles account for the diversity of real estate production strategies ob-
\end{abstract}

Letra de la canción "Joya del Pacífico", vals popular escrito en 1941 y popularizado por el cantante Jorge "Negro" Farías. Dedicada a Valparaíso, en su estrofa la canción representa la particularidad de su geografía y paisaje: anfiteatro natural que permite observar, desde casi cualquier punto, sus cerros, plan y mar.

Esta investigación fue financiada por el proyecto CSOC 02-18 "La heterogeneidad de formas de producción del hábitat. El caso de Valparaíso" de la Dirección General de Investigación, Universidad de Playa Ancha, Valparaíso, Chile.

Instituto de Geografía, Pontificia Universidad Católica de Chile. Correo electrónico: cdvergara1@uc.cl

Carrera de Sociología, Universidad de Playa Ancha. Correo electrónico: nelson.carroza@upla.cl 
served within the city. Likewise, it is established that the average income obtained by real estate companies triples the capitalization of those who obtain rent by selling the land.

Keywords: real estate development, housing, urban planning, urban geography

Diversas corrientes del pensamiento geográfico han planteado la importancia de la dimensión espacial como una categoría analítica imprescindible para comprender los procesos de acumulación y reproducción del capital (Lefebvre, 2015; Castells, 1976; Harvey, 2017; Brenner, 2013; Slater, 2009; Smith, 2012). En diálogo con los patrones de las economías periféricas, estos supuestos permiten evidenciar que la intensificación de la ciudad como un escenario de especulación, captura y acumulación de renta urbana es, sobre todo, un elemento determinante en la profundización y reproducción de desigualdades socioterritoriales (Santos, 1990; Kowarik, 1996; De Mattos, 2006; Rolnik, 2017). Más allá de su heterogeneidad, estas perspectivas permiten comprender que los procesos de desigualdad socioespacial se cristalizan en las peculiaridades de las estructuras económicas y políticas que sustentan la transformación de las ciudades. Y, actualmente, estas estructuras se hallan determinadas por las múltiples dinámicas de producción espacial que guardan una relación isomorfa con las lógicas de acumulación del capital global.

En Chile este modelo de producción de ciudad encuentra sus fundamentos en las transformaciones políticas urbanas iniciadas hace casi cuarenta años (De Mattos, 1999; Hidalgo, 2002; Rodríguez \& Sugranyes, 2004). Por un lado, en la década de los ochenta, la liberación del mercado de suelo consolida al sector privado como un actor estratégico en la tenencia, compra y venta de terrenos urbanos. Con esto, se consigue suplantar la noción de suelo regulado y garantizado por el Estado, por la noción de suelo como bien de mercado (Sabatini, 2000). Por otro lado, en la misma década, se plantean las bases de una nueva política de vivienda sustentada en la interrelación entre el sector inmobiliario, el financiero y un sistema de subsidios estatales focalizados. Así, en la producción de vivienda para la población de menores ingresos, se promueve la masividad y cantidad por sobre la cualidad y calidad (Hidalgo et al., 2016; Rodríguez \& Sugranyes, 2004; Tiro$\mathrm{ni}$, 2003). Tanto las inspiraciones ideológicas como los diversos instrumentos político-técnicos de estos procesos concomitantes han sido el contexto desde el que se han encauzado las principales transformaciones urbanas chilenas en las últimas décadas.

En estas condiciones, la industria inmobiliaria ha promovido diversas estrategias para su desarrollo. En los últimos años sobresalen los proyectos habitacionales de gran escala y alta densidad. Fundamentalmente, este negocio se vincularía con la obtención de renta mediante la revalorización del suelo urbano a través de cuatro estrategias: (a) desarrollo de proyectos en terrenos considerados tradicionalmente de baja plusvalía, situación que permite la captura de rentas mediante el valor final de venta de la vivienda (Sabatini \& Cáceres, 2004; Sabatini, 2003); (b) densificación de ciertos sectores de la ciudad, por medio de acuerdos de promoción público-privados, expresados en diversos instrumentos e incentivos para el desarrollo inmobiliario (López-Morales et al., 2012; 2014); (c) captura de plusvalías mediante la apropiación y aprovechamiento de activos paisajísticos, naturales y/o patrimoniales de los territorios (Hidalgo \& Arenas, 2012; Hidalgo et al., 2018; Vergara-Constela \& Casellas, 2016); y (d) proyectos inmobiliarios que capitalizan su inversión mediante la localización próxima a inversiones públicas de gran escala (López-Morales et al., 2019). Estas estrategias inmobiliarias -obviamente combinadas- han implosionado y explosionado el espacio urbano (Lefebvre, 2015). Más aún, este fenómeno suscita un reajuste 
en el patrón de asentamiento tradicional de los territorios y acarrea importantes externalidades regresivas para sus residentes. De este modo, surgen demandas comunes por parte de quienes han sido afectados, y se establecen marcos de acción colectiva y reorganización comunitaria que impugnan este modelo de creación de ciudad (Casgrain \& Janoschka, 2013; Hidalgo et al., 2015; Vergara-Constela, 2019).

El caso particular de la comuna de Valparaíso ha sido poco investigado respecto a las dinámicas del mercado de suelo urbano. Con posterioridad a la denominación patrimonial de 2003, las investigaciones han tendido a enfocarse en las lógicas y los efectos del nuevo estatus del que goza la ciudad. Ya sea desde las políticas de reactivación urbana (Andueza, 2010), los dispositivos gubernamentales de la implantación patrimonial (Aravena \& Sobarzo, 2009), o bien, desde la emergencia de procesos de gentrificación (Vergara-Constela \& Casellas, 2016; Opillard, 2016; Cáceres, 2019), buena parte de la producción de los análisis ha estado enfocada dentro de los márgenes del concepto de sitio UNESCO. Amparada en la explotación del paisaje urbano, esta denominación trajo aparejada la disminución de usos habitacionales, junto con la diferenciación de espacios entre la zona portuaria y los cerros vinculados a la élite anglosajona. Todo ello, en el marco de una dialéctica entre degradación y revitalización barrial (Hidalgo et al., 2014).

En la comuna de Valparaíso, lo paisajístico se erige como un valor identitario central (Ponce et al., 2016). Por lo mismo, la imposibilidad de apreciarlo se comprende como la afección a un bien común que constituye un capital simbólico colectivo (Guerrero, 2012). Atribuir las causas de esta afección a la fase neoliberal de la urbanización constituiría un error, puesto que, desde la década de los sesenta, tanto el Estado como otros agentes han construido grandes volúmenes, principalmente en el centro de la ciudad (Opazo, 2016). Con todo, y más allá de quien la promueva, la edificación en altura ha sido indicada como una problemática sentida por la ciudadanía porteña.

En los apartados que siguen, dos preguntas articulan este trabajo: ¿cómo ha sido, entonces, el desarrollo de la edificación en altura dentro de Valparaíso en las últimas décadas?, ¿bajo qué lógicas se encuentra inmerso este desarrollo? Para abordar estas interrogantes, se analizará la producción material de la oferta de vivienda privada en altura dentro del área urbana de la comuna de Valparaíso durante las últimas tres décadas. Con este propósito, se revisará la superficie construida, su cantidad, localización y las rentas obtenidas según año y zona de la ciudad (plan y cerros).

Entendiendo que esta actividad económica contempla la remoción de recursos naturales, además de la apropiación privada de recursos colectivos y bienes comunes, proponemos que en Valparaíso se observa el avance sostenido de lógicas propias de un extractivismo urbano que se halla respaldado por la administración pública local y nacional, y que se relaciona con los procesos de modernización de la ciudad.

\section{Extractivismo urbano y renta de suelo}

Una de las características fundamentales de la matriz productiva de las economías latinoamericanas ha sido la explotación y la extracción intensivas de recursos naturales -petroleros, mineros, agrarios, forestales y pesqueros-. Promovidas por capitales extranjeros y orientadas a 
la demanda de los mercados internacionales, estas actividades han implicado impactos ambientales y sociales negativos. Todavía más, han devenido expresión material de un tipo de desarrollo propio de las economías dependientes y periféricas de la región (Alimonda, 2011; Gudynas, 2009; Acosta, 2012; Svampa, 2012).

Para comprender las continuidades y rupturas respecto al extractivismo tradicional, diversos autores han propuesto categorías relacionadas con la pluridimensionalidad y multiescalaridad de estos procesos. Así, el neoextractivismo (Gudynas, 2009; Acosta, 2012; Svampa, 2012) surge como un modelo de desarrollo que profundiza y extiende la escala de explotación de recursos. La legitimación de este modelo por parte de gobiernos progresistas - o "el consenso de los commodities" según Svampa (2012) - ha situado al Estado no solo como ente facilitador de la inversión, sino también como productor y/o controlador de este tipo de actividades (Gudynas, 2009).

Por cierto, este modelo de desarrollo no está exento de contradicciones (Gaudichaud et al., 2019). Por un lado, parte de los excedentes generados por estas actividades ha permitido financiar importantes programas sociales. Pero, por otro lado, los impactos medioambientales de estas actividades dañan irreversiblemente el metabolismo social (Acosta, 2012; Paulsen, 2019) y afianzan un patrón de acumulación. Por añadidura, como modelo de ocupación territorial, las actividades extractivas desplazan otras formas económicas, lo que deriva en esquilmo y expolio, y, en definitiva, agudiza la conflictividad social y la resistencia en estos territorios (Hidalgo et al., 2016b; Svampa, 2019; García Jerez, 2019).

Instituidos sobre la importancia del sector inmobiliario en la producción del espacio urbano, diversos autores han propuesto el concepto de "extractivismo urbano" para contextualizar los procesos anteriores en las ciudades de América Latina (Arenas et al., 2016; García Jerez, 2019; Viale, 2017; Pintos, 2017). En esta línea, se ha puesto el acento en los procesos de la mercantilización del suelo urbano, mediante la producción de segundas naturalezas. Con ello, no solo la remoción en masa de tierra sino que la extracción de arena y grava desde mares o ríos para posibilitar la mezcla del hormigón, es determinante para otorgar intensidad en la producción de vivienda, posibilitando las condiciones para la extracción de renta del suelo, dinamizando la circulación de capital y alimentando al segundo circuito de la economía (Santana, 2019). Entonces, al igual que otras actividades extractivas, el extractivismo urbano también ha evidenciado consecuencias sociales y ecológicas de estas formas de producir espacio que han gatillado la expulsión, desposesión y expolio. Y, todo esto se debe, en gran parte, a la intervención o destrucción de áreas naturales (con o sin protección), al agotamiento y/o sobrecarga de recursos urbanos (e.g., espacios públicos, paisajes, parques o redes de alcantarillado) y al aumento de diversos tipos de contaminación (e.g., acústico, emisión de gases, huella ecológica o sobrecarga de los residuos domiciliarios). En términos concretos, el capitalismo transforma la naturaleza sobre la base de su potencial mercantil dentro de algunas de las fases del proceso productivo.

En este sentido, la lógica extractiva con la que opera el capital implica su territorialización. Precisamente, lo que Harvey (1990) ha denominado solución/fijación espacial -spatial fix- da cuenta de las formas de circulación del capital hacia espacios aún no explotados, con el fin de mantener tasas de ganancia mediante la extracción de renta. Para Marx (2015), la renta de la tierra posee dos componentes fundamentales: su carácter monopólico, en cuanto ninguna porción de suelo puede parecerse a otra; y el aumento de su precio, producto del incremento de población 
y/o del bienestar de la zona. Desde esta base, el estudio de la renta del suelo en las ciudades ha permitido analizar la urbanización en relación con la diferenciación social. Desde una perspectiva estructuralista, Topalov (1984) va a sostener que toda renta urbana es una renta situacional, por lo que posee un carácter netamente diferencial. Esto implica la (re)producción de jerarquías espaciales, dada la imposibilidad de homologar las características de un suelo determinado a las de otro. En esta lógica, lo que permite apropiarse de una renta es la obtención de su control jurídico. De esto se desprende que, en el mercado del suelo, no se tranzan valores sino propiedades (Topalov, 1984; Jaramillo, 2010; Smith, 2012).

Específicamente, se puede considerar la renta del suelo como la posibilidad de capitalizar un precio de suelo de manera privada, a partir de un marco de posibilidades dadas por la sumatoria de valores de usos asociados a esa localización. De acuerdo con esta formulación, Topalov (1979) señala que la renta puede variar según la valorización diferencial del capital en concomitancia con la localización en el espacio urbano. Ahora bien, para comprender la relación entre espacio y capital, resulta necesario distinguir valor, precio y renta. Smith (2012) indica que el valor de una vivienda (emplazada en una porción de suelo) depende de la cantidad de trabajo realizado para construirla, lo que solo adquiere la forma de precio en una transacción mercantil. De manera consecuente, el precio en que se estima la venta de una vivienda implica considerar el trabajo realizado y la expresión del plusvalor en el salario como en la renta del suelo. De ahí la emergencia de dos tipos de rentas del suelo: una que corresponde a quien posee la propiedad del predio y que es capitalizable en operaciones de compra-venta o arriendo; $y$ otra potencial, capitalizable a partir de un desarrollo del suelo más intenso, según las condiciones sociales y jurídicas existentes.

Sobre este particular, Ramas (2015) plantea una aclaración: cuando se compra suelo, por ejemplo, para "desarrollo urbano", se compra el control del valor de uso de esa porción de tierra. Es sabido que, en cualquier actividad económica, el suelo es la fuente de todo plusvalor; por lo mismo, aparece "disfrazado como precio de suelo". En este sentido, Ramas se pregunta: ¿cómo puede la tierra (suelo) entregar un plusvalor si el valor equivale esencialmente al trabajo realizado? Y desde ahí, también, cabe preguntarse: ¿cómo puede el suelo valorizarse según diferencias de localización? Ramas argumenta que la renta del suelo está ceñida a una forma mistificada, pues, esconde la mediación "cristalizada en el precio" entre trabajo productivo y asalariado. Esta relación esencial genera, por ende, plusvalor, ya que el ingreso es reducido solamente a la posesión del bien.

En definitiva, reconocer estos procesos urbanos a través del prisma del extractivismo urbano nos permite profundizar y reconocer una matriz del proceso de acumulación y reproducción de capital, donde la renta del suelo define la expresión concreta de la ganancia y modificación del entorno construido. En este sentido, esta perspectiva nos permite comprender como la lógica neoliberal urbana transforma la dimensión socio ecológica del territorio, no solo como consecuencia del proceso de acumulación, sino más bien, como una dimensión articuladora y ordenadora del proceso de creación y reproducción de lo urbano. Lo anterior, a través de sucesivas olas modernizadoras, donde el Estado y los actores privados, operan como garantes y catalizadores de operaciones mercantiles de extracción de plusvalor en forma de renta de suelo en las ciudades de América Latina. 


\section{Catastrando la edificación en altura y la extracción de renta de suelo en la comuna de Valparaíso}

Para esta investigación, la producción de datos se realizó mediante el catastro de cada uno de los edificios de cuatro o más pisos construidos entre 1991 y 2017, que constituyen la oferta privada de vivienda del área urbana de Valparaíso. Este catastro visibilizó el total de 82 proyectos inmobiliarios que se erigen como el universo del estudio ${ }^{5}$.

El procedimiento para completar esta información fue el siguiente. Primero, se identificó la localización de los edificios, siendo asociados a un rol de cobro entregado por el Servicio de Impuestos Internos (SII). Luego, con el rol identificado, se solicitó acceso a la Dirección de Obras de la Municipalidad (DOM) de Valparaíso, para revisar las carpetas de antecedentes de cada propiedad. Esto permitió construir una base datos con las siguientes variables: rol, predio, dirección, cerro o zona, nombre de inmobiliaria, nombre de constructora, superficie predial final, superficie edificada, pisos, subterráneos, zona PRC, año de otorgamiento del permiso, cantidad de departamentos, cantidad de estacionamientos, cantidad de habitaciones (baños y dormitorios), presupuesto de la obra y antecedentes de pago de derechos municipales. Enseguida, se complementó esta base con visitas al Conservador de Bienes Raíces (CBR), donde se encuentra registrada la historia de cada propiedad inmueble de la ciudad. Alli se completó la base identificando tanto el precio, pagado por las inmobiliarias a quienes eran dueños de los predios, como los precios en que fueron vendidos los departamentos. Finalmente, estos datos permitieron estimar las rentas obtenidas $^{6}$.

A partir de la discusión conceptual presentada, se puede dar cuenta operativamente de dos tipos de renta: RCS-1 y RCS-2. Sobre la base de estas, se obtiene el cálculo de la brecha de renta en cuestión. Para esto, se tomaron definiciones provenientes de estudios internacionales (Smith, 2012; Clark, 1988), contextualizados a la realidad chilena (López-Morales, 2013) y, particularmente, a una comuna de la región de Valparaíso (Azocar \& Vergara-Constela, 2019). Para calcular la renta capitalizada por propietarios (personas naturales y/o jurídicas) en terrenos donde luego se levantaron proyectos de edificación en altura (RCS-1), se revisaron las transacciones de estas propiedades en el CBR, en particular, aquellas donde el valor final de la variable da cuenta de la media de la renta obtenida por los antiguos propietarios. A su vez, la renta de suelo capitalizada por el desarrollador inmobiliario (RCS-2) corresponde a la sumatoria de las ventas de cada una de las unidades de vivienda. A este valor, se le restó el precio pagado por el suelo correspondiente a los predios, los costos de construcción y los derechos municipales. Y, acto seguido, este valor resultante fue dividido por la cantidad de superficie del terreno ${ }^{7}$. Finalmente, la brecha de renta

\footnotetext{
Del total de proyectos catastrados dentro del periodo estudiado, se excluyen diez proyectos inmobiliarios: de ellos, seis se encuentran judicializados, o bien, afectos a recursos invalidatorios administrativos. Por esta razón, aún no es posible saber si se venderán o no. Con respecto a los cuatro restantes, no fue posible acceder a información oficial en la DOM.

6 Aquí, cabe explicitar tres puntos: (a) los precios de cada una de las compra-ventas fueron homologados al precio del peso chileno en 2017; (b) luego, estos precios se traspasaron a unidades de fomento (UF), medida en que se valoriza la vivienda en Chile; (c) por último y, dado que en el CBR no estaba la totalidad de las compra-ventas de departamentos, la renta obtenida por el desarrollador inmobiliario se estimó a la baja, es decir, se asumieron los precios más bajos de compra-venta para ser ampliados a la totalidad de las unidades de vivienda - por consiguiente, no se lograron diferenciar los precios de distintas tipologías de departamentos-. Planteadas así las cosas, la renta obtenida por los desarrolladores inmobiliarios es, por lo menos, la que se expone en los apartados siguientes.

Tal como se ha señalado en otros estudios, por tratarse de una estimación, se parte del supuesto de que cada una de las unidades de vivienda ha sido vendida.
} 
corresponde a la ganancia obtenida por las inmobiliarias. De manera sintética, la fórmula de cálculo es (RCS-1 - RCS-2)/ superficie de predio.

Cabe señalar que, debido a que en la DOM y en el CBR existían algunos proyectos puntuales donde faltaba información, se decidió formular algunas precisiones. Para dar cuenta de la caracterización general de los proyectos inmobiliarios, se ocuparon todos los datos existentes desde 1991 a la fecha, mientras que para realizar el cálculo de la extracción de renta, se comprendieron datos desde 1996 a la fecha. En definitiva, la metodología empleada presentó algunas limitaciones. Por lo mismo, se debe recalcar que aquí se ofrece una estimación de las rentas que depende de la información disponible en las fuentes oficiales - muchas veces archivada de manera deficiente-. Por último, debe consignarse que la temporalidad con la que se trabaja corresponde a las fechas de aprobación de los permisos entregadas por los municipios, cuestión que difiere de las fechas de construcción y entrega de los proyectos inmobiliarios.

\section{La reconversión de Valparaíso: matriz productiva y formas de urbanización}

Tal como otras ciudades-puerto en el mundo, Valparaíso ha experimentado cambios relevantes en su plataforma económica y urbana en las últimas décadas. Constituida como una urbe compacta, nodo logístico, industrial y comercial durante gran parte del siglo $\mathrm{XX}$, ha transformado su vocación productiva combinando funciones portuarias con actividades turísticas, patrimoniales y universitarias (Aravena \& Sobarzo, 2009; Carroza \& Valenzuela, 2011).

Es importante situar el tránsito de su repertorio productivo en la pérdida de gravitación de las actividades portuarias e industriales durante la década de los ochenta (Leal y Aguirre, 2020; Alarcón, 2009). Esto se expresó tanto en el cierre o relocalización de alrededor de 80 industrias de la región, como en la caída de un $18,4 \%$ del PIB industrial regional entre las décadas de 1960 y 1990 (Carroza \& Valenzuela, 2011). Por añadidura, el proceso de desindustrialización ha promovido la discusión en torno al carácter inconcluso de la reconversión productiva de Valparaíso y sus consecuencias en el modelo de desarrollo económico actual de la ciudad (Carroza \& Valenzuela, 2010; Muga \& Rivas, 2007). Paralelamente, la emergencia de una nueva plataforma económica y urbana, caracterizada por una economía de servicios -turísticos, patrimoniales y universitarios-, ha propiciado una nueva forma de comprender el desarrollo de la ciudad 8 .

En este marco, el área de la construcción se ha erguido como un rubro estratégico en la economía de la región, cuestión que se ve reflejada en factores tales como la acelerada (re)urbanización del borde costero del área metropolitana, la producción de vivienda social en las periferias comunales y la producción de vivienda en condominios hacia las comunas del interior (Hidalgo \& Borsdorf, 2005).

Uno de los aspectos discutidos son las características del empleo generado en el contexto de esta matriz productiva. Así, durante la década anterior, diversos trabajos demostraron el proceso de segmentación de su mercado laboral, expresado en las diferencias entre las características de los trabajadores de mayor cualificación y las del resto de los estratos, estos últimos singularizados por tasas de desempleo más elevadas, mayores diferencias de ingresos y empleos signados por la informalidad y/o precariedad (Carroza y Valenzuela, 2010, 2011). 
Las formas de urbanización en la comuna de Valparaíso poseen matices variados. Para efectos de este estudio, se constatan los siguientes:

Urbanización informal. Materializada por medio de tomas de terreno, esta práctica posee una larga tradición como mecanismo de solución habitacional. Según Pino y Ojeda (2013), su fundamento radica en el despliegue de estrategias familiares de reproducción social. Actualmente, persiste de diferentes maneras: densificación en predios regularizados, tomas que definen expansiones de la trama o pequeños asentamientos en laderas más o menos habitadas. De manera interesante, Bonilla et al. (2018) indican que los terremotos se han convertido en vectores de este tipo de urbanización en las zonas más altas de los cerros. A su vez, Carramiñana (2016) ha demostrado cómo en la década de 1990 la zona consolidada del cerro Cordillera tendía hacia el despoblamiento, mientras que las laderas de las zonas baja y alta se comenzaban a poblar con gente del mismo cerro y de otros lugares mediante viviendas no formalizadas.

Proyectos inmobiliarios suburbanos. La expansión urbana de Valparaíso ha estado notablemente influida por el desarrollo del proyecto inmobiliario suburbano de Curauma, ubicado en Placilla de Peñuelas. Desde inicios de siglo, se ha consolidado como una subcentralidad metropolitana gracias a la concentración universidades, supermercados, colegios, gimnasios, centros comerciales y canchas de futbol (Mansilla \& Fuenzalida, 2010). Además, por su buena conexión con la red de autopistas intra e interurbanas ha contribuido a articular la macrozona urbana del centro de Chile.

Dispositivo patrimonial. La activación de este dispositivo ha conllevado la extensión del centro comercial hacia la zona patrimonial (Hidalgo et al., 2014; Vergara-Constela \& Casellas, 2016; Cáceres, 2019). Junto con ello, se han dinamizado circuitos de arriendo que han acarreado consecuencias tales como el reemplazo de población (Marín et al., 2017), el surgimiento de la nueva vivienda renovada en pequeños departamentos o lofts, o incluso la okupación de inmuebles abandonados en las áreas centrales (Venegas, 2014).

Figura No1.

Superficie de departamentos construidos en Valparaíso (2002-2018)

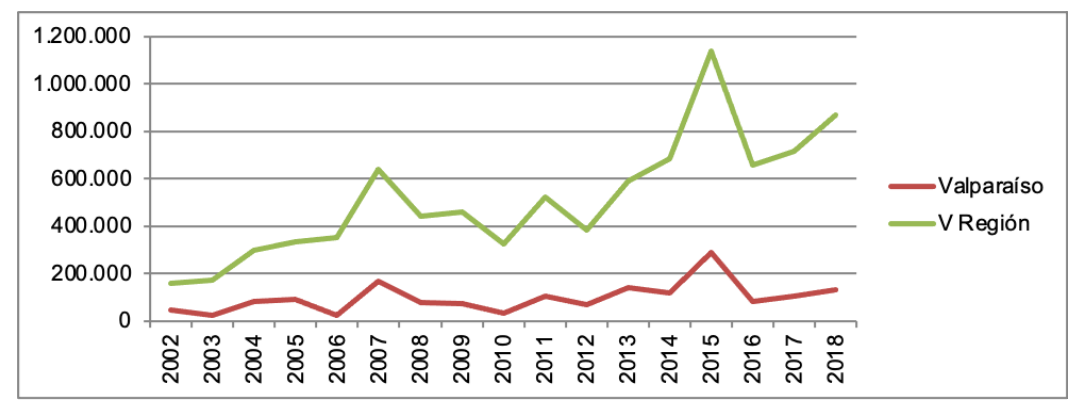

Fuente: Elaboración propia sobre la base del Observatorio Habitacional, del Ministerio de Vivienda y Urbanismo (2019).

Programas de vivienda social. Efectuadas mediante subsidios estatales, estas iniciativas se han localizado preferentemente en las zonas más cercanas al límite urbano comunal (Hidalgo et 
al., 2018). Desde la década de 1990 se constata la ubicación de edificios en las últimas laderas del área urbana de los cerros Playa Ancha, Los Placeres y Rodelillo, y, de manera reciente, en las inmediaciones de los cerros La Cruz, Rocuant y Placilla.

El hecho de que el parque de vivienda haya aumentado más respecto a la tasa de crecimiento poblacional resulta decidor (Hidalgo et al., 2016b). De forma ineludible, expone las funciones residencial-universitaria y turística que las áreas centrales de Valparaíso (y su vecina Viña del Mar) están cumpliendo. Y esta presión generada por el desarrollo intenso del suelo ha tenido consecuencias inmediatas: la degradación ambiental, por una parte, y la mercantilización de valores paisajísticos, por otra (Fuentes \& Pezoa, 2017; Arenas et al., 2016; Panez, 2015).

\section{Dinámicas de producción inmobiliaria en Valparaíso (1991-2017)}

En las últimas tres décadas, es posible reconocer tres etapas en la producción de edificaciones en altura dentro del área urbana de Valparaíso. Un primer periodo (1996-2001) se caracterizó por el crecimiento moderado de la construcción en altura, representado tanto en el número de proyectos (Figura $\mathrm{N}^{\circ} 3$ ) como en los metros cuadrados construidos anualmente (Figura $\mathrm{N}^{\circ} 4$ ). Durante esta fase, se aprobaron 12 proyectos, distribuidos en cerros y territorios que luego serían los sectores más representativos de la producción inmobiliaria en la ciudad: los cerros Alegre, Delicias, Barón y Los Placeres (Figura N05). Las tipologías combinan edificios de gran altura con otros de menor envergadura.

En este periodo, las posibilidades para la industria de la construcción estaban en un punto contradictorio. Por un lado, las condiciones de edificación plasmadas en el Plan Regulador Comunal de 1984 poseían un carácter permisivo y favorable para la densificación en altura. Esto, en consonancia con el espíritu gubernamental urbano de la época, que diseñó instrumentos de diversa índole para agilizar el protagonismo privado en la producción habitacional y el desarrollo urbano (Daher, 1991). En la dinámica inmobiliaria, este parece ser un periodo de apresto. Tal como ha demostrado Opazo (2016), durante la década de los ochenta se constató una incipiente industria de la construcción en las zonas de Barón, Playa Ancha y el plan (específicamente en El Almendral).

Por otro lado, Vargas-Francia (2018) indica que esta etapa $-y$, particularmente, la década de 1990- fue dominada por un discurso público que subrayaba el deterioro urbano y, por ende, la necesidad de desplegar políticas de renovación. Este discurso iba aparejado a la pérdida de condiciones de habitabilidad de la zona urbana de la ciudad y a la pérdida de población observada en el decenio 1992-2002 (Hidalgo \& Borsdorf, 2005; Carroza \& Valenzuela, 2010). Precisamente, en este momento emergen nuevas alianzas entre el ámbito público, el privado y la sociedad civil, cuyo fin es capitalizar el "legado histórico" de la ciudad mediante su patrimonialización. Además, durante estos años, la inversión del mundo inmobiliario estuvo centrada en la renovación de la población Vergara en Viña del Mar (Valdebenito, 2017) y la invención de la suburbanización de Curauma, en la zona de Placilla - parte de la comuna de Valparaíso- (Mansilla \& Fuenzalida, 2010). Aún así, en Valparaíso se construyeron edificios en zonas relativamente centrales tales como Cerro Yungay (Figura $\mathrm{N}^{\circ} 2$ ). 
Figura $\mathrm{N}^{\circ} 2$.

Edificación en altura en calle General Mackena, Cerro Yungay

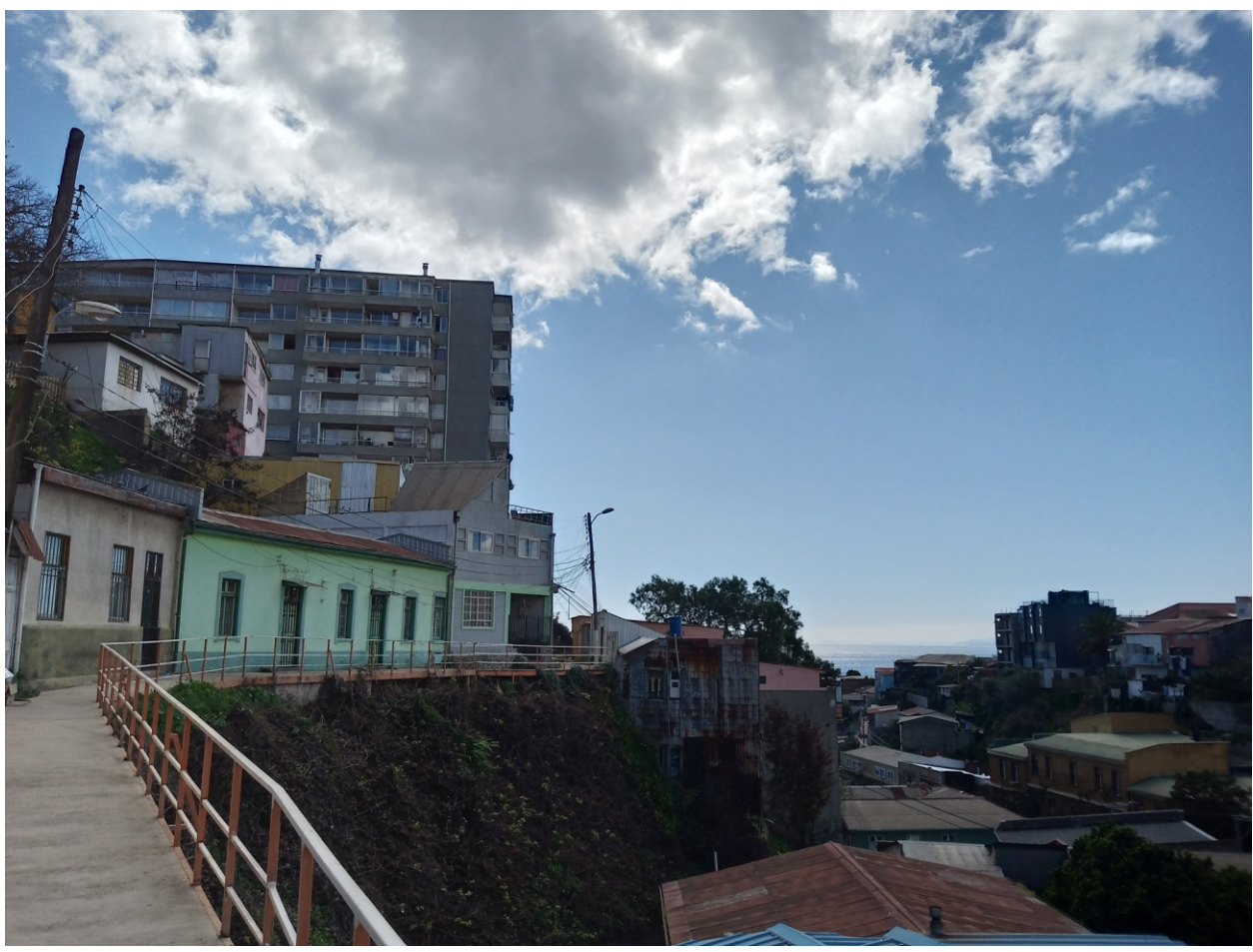

Fuente: Elaboración propia, archivo de autores.

Figura No3.

Promedio anual de metros cuadrados construidos

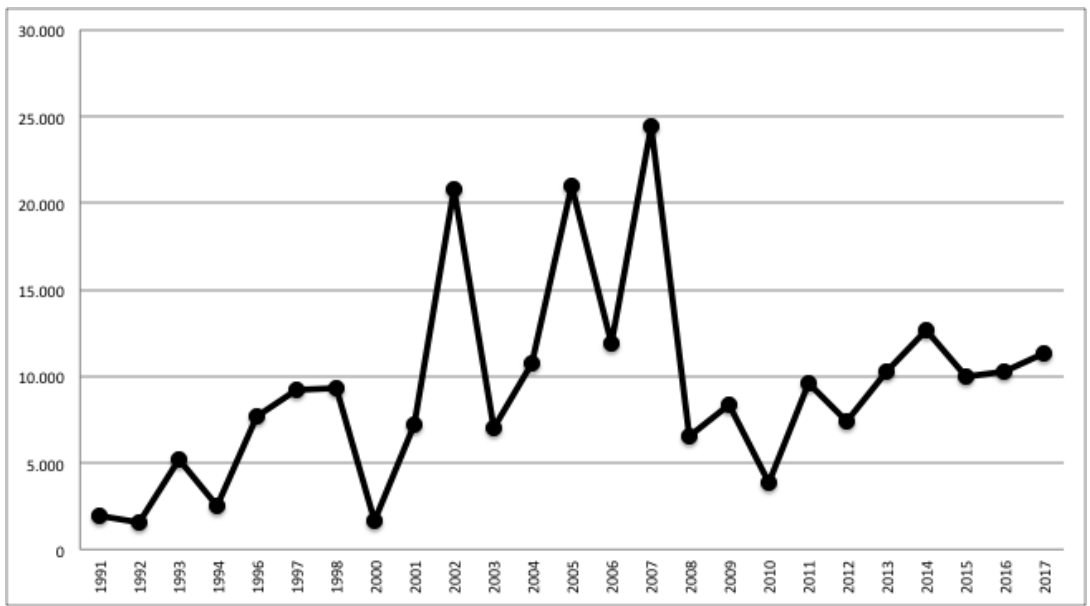

Fuente: Elaboración propia.

Figura $\mathrm{N}^{\circ} 4$. 
Cantidad de proyectos inmobiliarios aprobados por año

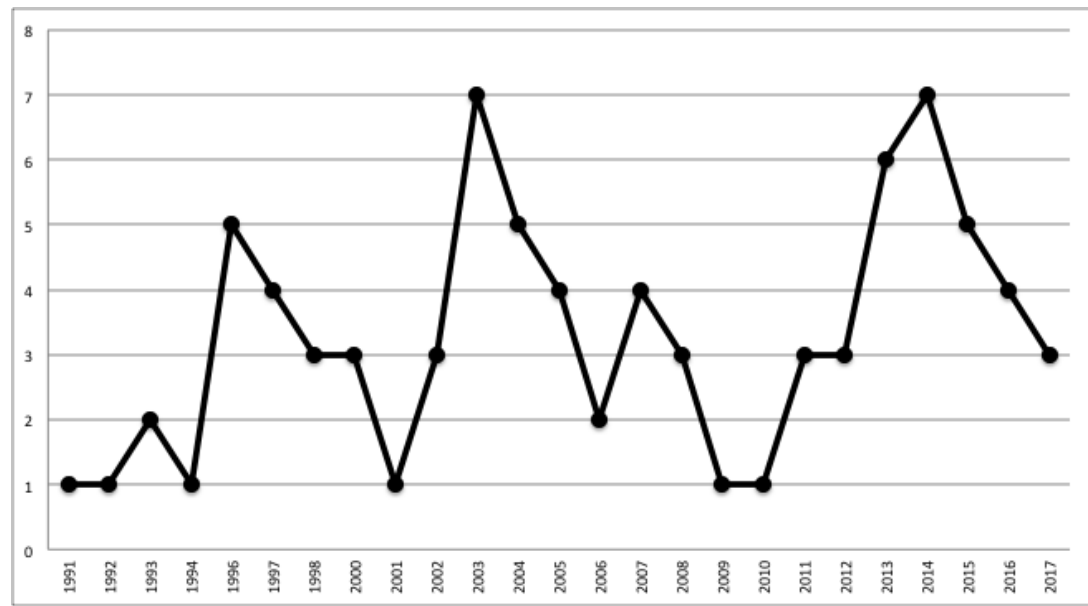

Fuente: Elaboración propia.

El segundo periodo (2002-2010) se distinguió por el crecimiento y la intensificación de la producción inmobiliaria. En efecto, solo en el transcurso de seis años (2002-2007), se aprobaron 25 proyectos que, en promedio, representan la mayor superficie de metros cuadrados construidos en el conjunto de periodos analizados $\left(395.420 \mathrm{~m}^{2}\right)$. Durante esta etapa, los proyectos continúan concentrándose en los cerros Barón, Los Placeres y Delicias. A estos se suman otros, como cerro San Roque, Larraín, Polanco y Florida (Figura N05). Dicho de otro modo, durante este periodo, se consolidan los territorios proyectados en la etapa anterior. En esta, la tipología representativa y dominante la componen los edificios de grandes alturas y dimensiones.

Figura No5.

Proyectos inmobiliarios en altura en Valparaíso (1996-2017)

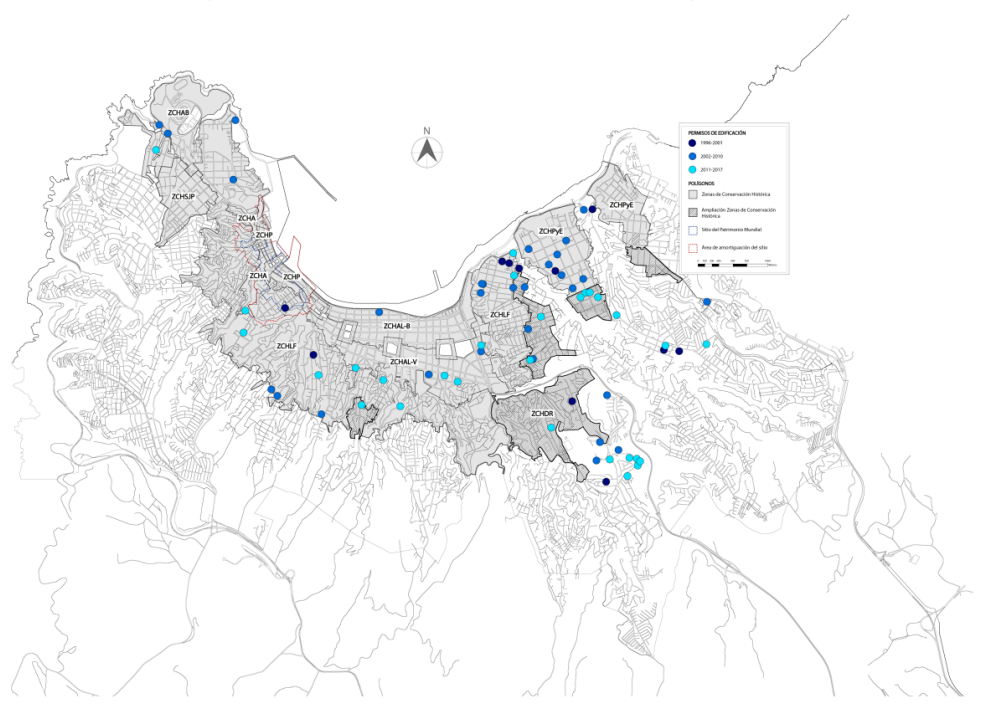

Fuente: Elaboración propia. 
Estos años están signados por los esfuerzos nacionales de situar a Valparaíso como patrimonio de la humanidad de la UNESCO. Este hecho estuvo enmarcado dentro del Plan Presidencial de Valparaíso y contemplaba una serie de políticas urbanas para revitalizar la ciudad. Tal como ha demostrado Andueza (2010), surgieron discursos en torno al repoblamiento y el potencial universitario-cultural. Estos discursos se entroncaron con el desarrollo de políticas públicas nacionales de aumento generalizado de la matrícula universitaria (Rodríguez, 2011). Para las instituciones de educación superior ubicadas en la conurbación Valparaíso-Viña del Mar, esto significó un aumento aproximado de un tercio de las matrículas y carreras (Vergara-Constela \& Casellas, 2016). El crecimiento de la cantidad de estudiantes tuvo como consecuencia la consolidación de algunos polos que contaban con infraestructura universitaria desde antaño: los cerros Playa Ancha y Los Placeres, además del plan (El Almendral). La figura 6, por ejemplo, da cuenta de una edificación construida en esa época, contigua a la Universidad de Playa Ancha. De todas maneras, resulta evidente que el crecimiento de la población universitaria dinamiza el mercado de alquiler en diversos puntos: desde la compra-venta de terrenos para nuevas edificaciones hasta el arriendo informal de habitaciones (Hochstenbach \& Boterman, 2015).

Ahora bien, todo el proceso de patrimonialización de Valparaíso significó modificaciones en los instrumentos de planificación urbana. En el año 2005 se promulgó una serie de Zonas de Conservación Histórica $\left(\mathrm{ZCH}^{9}\right)$, cuyo objetivo era preservar las condiciones paisajísticas por las cuales la ciudad había sido reconocida ${ }^{10}$. Un concepto interesante que aparece en las ordenanzas locales -y sin correlato con la normativa urbana nacional- es el de "copropiedad del ojo", cuestión que se ha traducido popularmente como el "derecho a la vista" (Guerrero, 2012).

No obstante, estas modificaciones al Plan Regulador Comunal fueron ineficaces, ya que se promulgaron con posterioridad al ingreso de muchos permisos de edificación. Además, produjeron la segmentación del espacio urbano en dos zonas segregadas: una zona baja con mayor regulación (máximo 14 metros en sitio eriazo, un piso más sobre lo construido o alturas según rasantes de vistas) y otra alta (de mitad de cerro hacia arriba) donde se mantuvieron las condiciones de edificación de la década de los ochenta. En este periodo también se comenzó a tramitar una nueva regulación que significó el ingreso de una gran cantidad de permisos de edificación en altura en las zonas que estarían sujetas a ella. De hecho, en el subperiodo 2003-2005, se ingresaron 15 permisos localizados en dichas zonas, concentrados mayoritariamente en el cerro Los Placeres. Se intensifica, de este modo, la conflictividad con este tipo de edificación, donde agrupaciones de habitantes identifican irregularidades en la aplicación de la normativa, o bien, impugnan esta forma de producción habitacional, en cuanto genera desplazamiento de habitantes y/o la imposibilidad de apreciar el paisaje (Guerrero, 2012).

\footnotetext{
La Zona de Conservación Histórica (ZCH) es denominación patrimonial considerada en los instrumentos de Planificación Urbana, específicamente en el Plan Regulador Comunal. Su importancia radica en la protección constitucional asociada al Dictamen 4.000 de la Contraloría General de la República de Chile y a la Ley de Bases Generales del Medio Ambiente N¹9.300.

10 Diario Oficial de la República de Chile, lunes 21 de marzo de 2005.
} 
Figura $\mathrm{N}^{\circ} 6$.

Edificación en altura en Avenida Playa Ancha, Playa Ancha

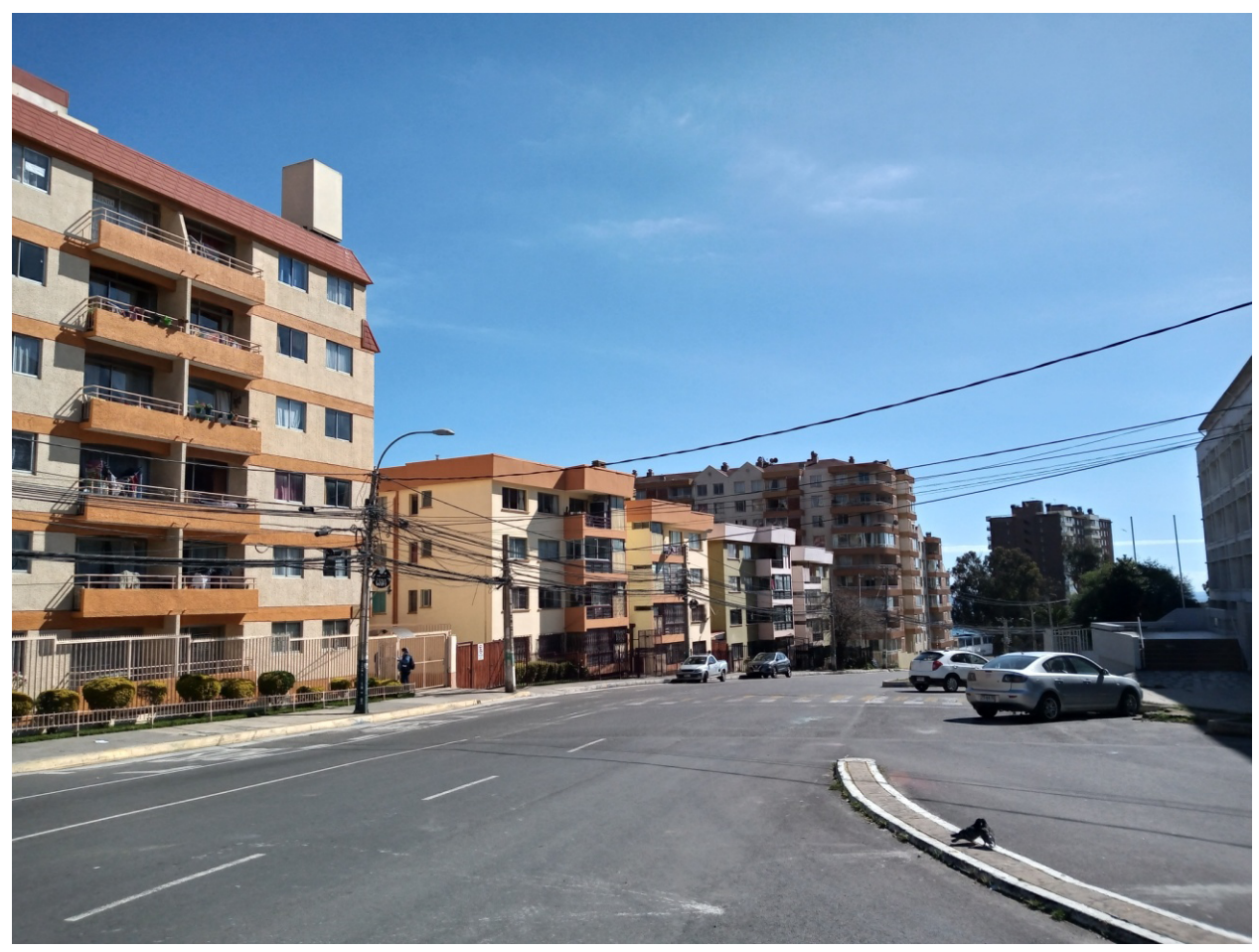

Fuente: Elaboración propia, archivo de autores.

Un tercer periodo de intensificación de la actividad inmobiliaria se da entre 2011 y 2017 . En esta época se aprueban 28 nuevos proyectos, con una importante superficie de metros cuadrados totales (312.304 $\mathrm{m}^{2}$ ); eso sí, la cifra es comparativamente menor a la del periodo anterior. Durante esta fase, la producción inmobiliaria se desarrolló en los territorios que ya concentraban edificación en altura. Además se intensificaron proyectos en el eje barrio Inglés (San Roque, $\mathrm{O}^{\prime}$ Higgins y Delicias; ver Figura $\mathrm{N}^{\circ} 7$ ) y se avanzó cerro arriba en la zona nororiente de la ciudad (Los Placeres-Barón). Así, estos espacios fueron singularizados por edificios de grandes alturas y dimensiones.

La regulación de las $\mathrm{ZCH}$, realizada a mediados del decenio anterior, produjo una segmentación aprovechada por la industria inmobiliaria. Se generó una constante en el emplazamiento de edificaciones en altura dentro del anfiteatro: se compran suelos una cuadra por sobre la línea donde limita la ZCH. Esta lógica fue aplicada en los cerros Los Placeres, Barón, Polanco, Monjas, Jiménez y Alegre. Por ejemplo, entre 2014 y 2015, se ensanchan las ZCH existentes en los cerros Monjas ${ }^{11}$ y Polanco, Los Placeres y Esperanza12, y se crean otras nuevas (Ramaditas y Barrio O'Higgins). Sin embargo, a medida que el área de regulación más estricta sube cerro arriba, la edificación en altura también lo hace.

Diario Oficial de la República de Chile, miércoles 11 de noviembre de 2014.

12 Diario Oficial de la República de Chile, miércoles 19 de noviembre de 2014. 
Figura N07.

Edificación en altura en calle Navío San Martín, San Roque

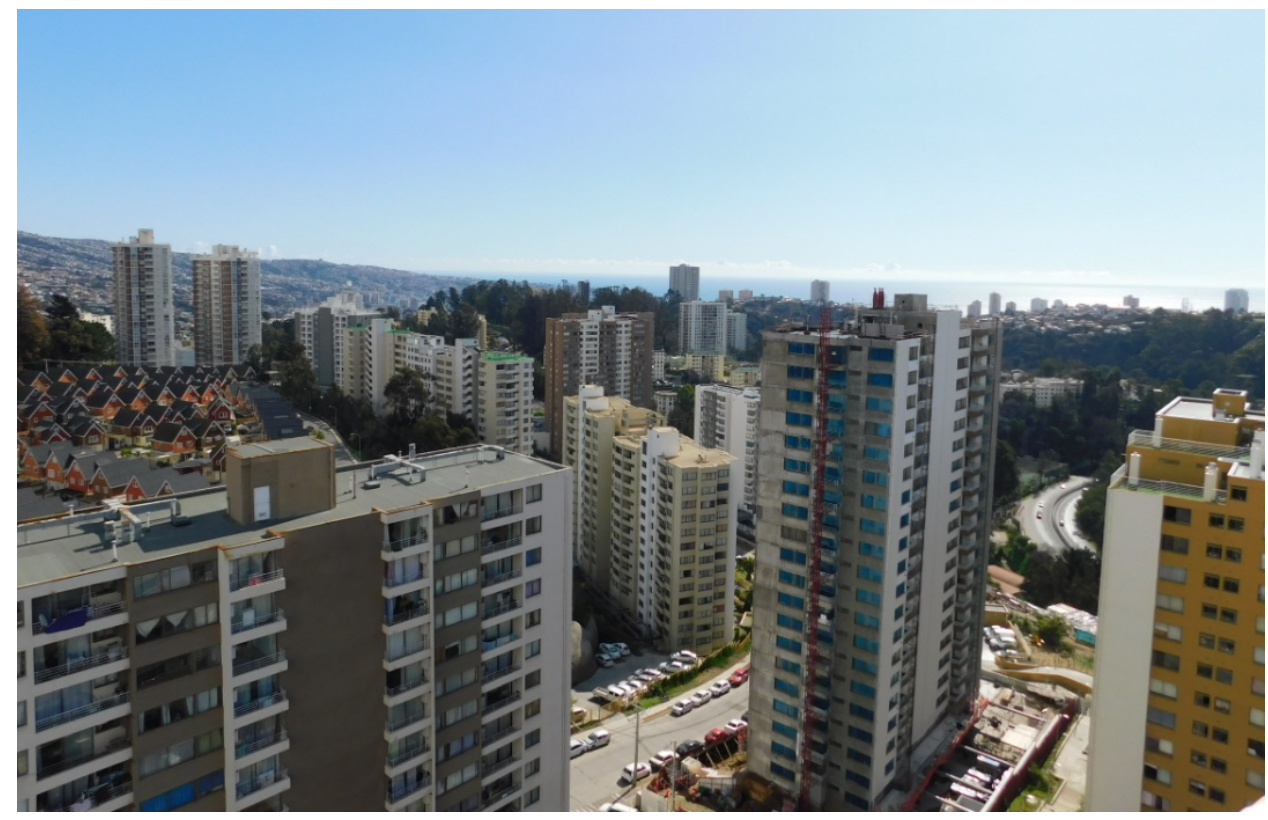

Fuente: Elaboración propia.

Figura No8.

Edificación en altura Cerro Monjas

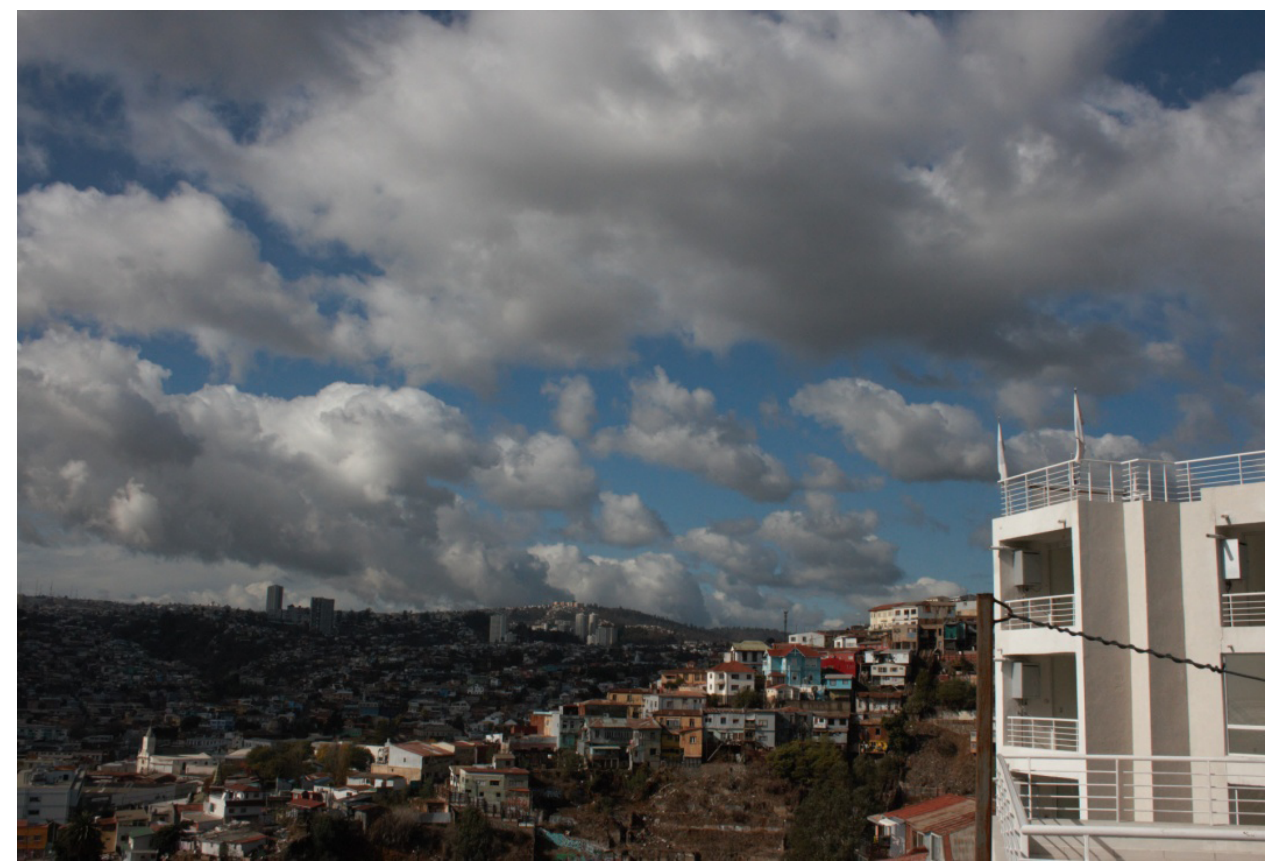

Fuente: Elaboración propia. 
Las urbanizaciones descritas vinieron acompañadas con la instalación de nuevos servicios, tales como bencineras o supermercados tipo retail. Un fenómeno similar ha ocurrido en los alrededores de la villa Berlín, zona media alta del cerro Los Placeres. Allí, se ha consolidado un polo de desarrollo inmobiliario en torno a la avenida Matta, vía estructurante del cerro. Esta área resulta estratégica, pues, posibilita la conectividad interna con Viña del Mar y con Agua Santa (ruta 68).

Resulta interesante constatar que, en este periodo, también se realizó edificación en altura de menor volumetría y bajo nuevas tipologías, tales como departamentos-estudio o lofts. En estos casos, los patrones de localización son ostensiblemente distintos: se ubican dentro de las $\mathrm{ZCH}$, adecuándose a las regulaciones más restrictivas y a predios más pequeños, pero aprovechando la proximidad al centro de la ciudad o a diferentes atractivos considerados patrimoniales (ascensores, paisajes, callejones). La figura 8 permite ver esto con claridad: edificaciones adecuadas a la normativa pero con un precio de venta mayor que la edificación en altura clásica. Con esto, se abren nuevas zonas, tales como los cerros La Cruz (eje avenida Francia) o Monjas (contiguo a un ascensor en proceso de rehabilitación; ver Figura $N^{\circ} 8$ ), o espacios del plan con mayor nivel de deterioro (El Almendral). Estas nuevas viviendas poseen un cariz más exclusivo y abren nuevas lógicas de producción inmobiliaria ante la impugnación recurrente de la edificación en altura mediante acciones colectivas (Vergara-Constela, 2019).

Figura No9.

Brecha de capitalización de renta de suelo en Valparaíso

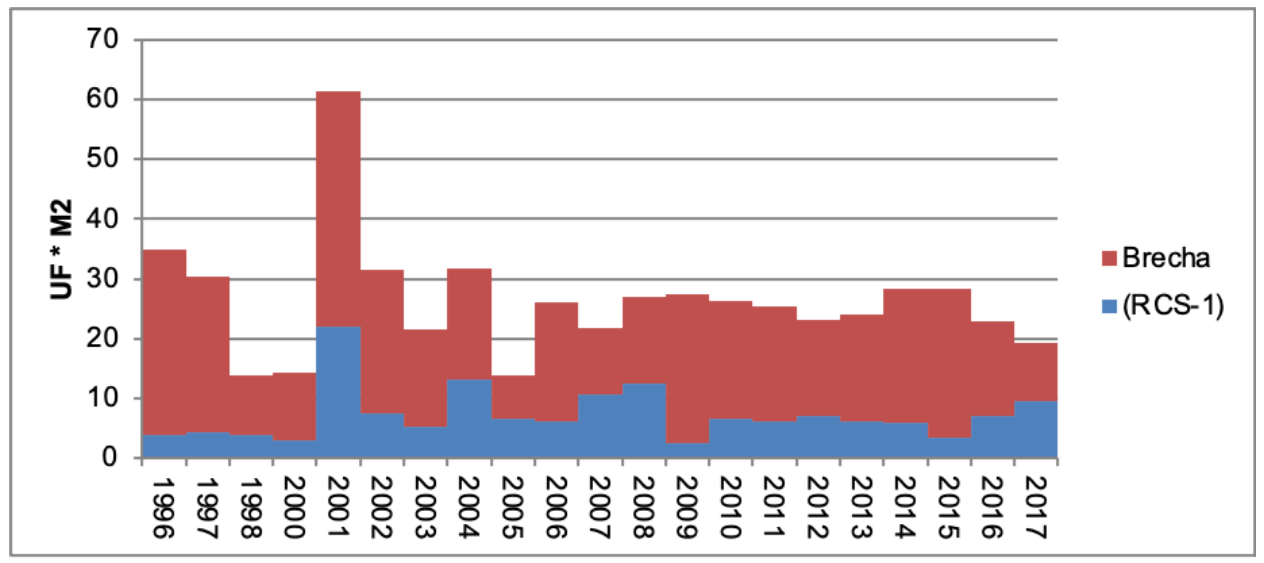

Fuente: Elaboración propia.

Entendiendo que la brecha de renta se constituye como las utilidades inmobiliarias obtenidas por proyectos desarrollados, en la Figura $\mathrm{N}^{\circ} \mathrm{g}$ se puede apreciar la amplia diferencia entre quienes tienen posibilidades de poder extraer una mayor renta del suelo y quienes solo pueden obtener una parte menor de esta compra-venta. Cabe mencionar que quienes logran capturar esta renta (RCS-1) no siempre son pequeños propietarios. Por el contrario, en muchos casos son entidades tales como congregaciones religiosas, sociedades de inversiones o antiguas cooperativas de vivienda que no completaron sus proyectos urbanizadores y decidieron vender suelos no desarrollados (así sucedió en Los Placeres o Esperanza). 
La dinámica de extracción de renta del suelo muestra que, durante los tres periodos analizados en conjunto, las inmobiliarias obtuvieron un promedio de $17,97 \mathrm{UF} / \mathrm{m}^{2}$, aproximadamente tres veces más que quienes pudieron capturar renta vendiendo suelo $\left(6,95 \mathrm{UF} / \mathrm{m}^{2}\right)$. De todas maneras, existen algunas diferencias interesantes si miramos periodos específicos. Por ejemplo, entre 1996 y 2000 , las utilidades inmobiliarias llegaron hasta $18,55 \mathrm{UF} / \mathrm{m}^{2}$, lo que disminuyó a $17,42 \mathrm{UF} / \mathrm{m}^{2}$ entre 2001 y 2007 , y a 15,61 UF/m² entre 2008 y 2010 -periodo de crisis-, para volver a aumentar considerablemente a 19,62 UF/m² entre 2011 y 2017. En tanto, quienes vendieron suelo para un desarrollo posterior, en promedio, no lograron capturar más de $10 \mathrm{UF} / \mathrm{m}^{2}$. Esta renta obtenida por pequeños propietarios es relativamente menor a las obtenidas en las zonas centrales y pericentrales del área metropolitana de Santiago, las que generalmente oscilan en torno a las $13 \mathrm{UF} /$ $\mathrm{m}^{2}$ (López-Morales, 2013). Sin embargo, esta renta es notablemente mayor que las obtenidas por pequeños propietarios de la comuna La Cruz, ubicada en medio de la conurbación Quillota-La Calera, la que en promedio no supera las 2 UF/m² (Azocar \& Vergara-Constela, 2019).

\section{Conclusiones}

Como se ha dicho, este trabajo analiza las dinámicas de producción inmobiliaria en altura del área privada al interior del cono urbano de la comuna de Valparaíso, durante las últimas tres décadas. Mediante la revisión pormenorizada de los proyectos -en particular, de las variables de superficie construida, localización y brechas de rentas obtenidas, según año y zona de la ciudad-, se reconocieron tres ciclos que dan cuenta de la diversidad de estrategias de la actividad inmobiliaria en la ciudad.

El primer periodo (1996-2001) se caracterizó por el crecimiento moderado de la construcción en altura, iniciándose la instalación en cerros y territorios que serían sectores estratégicos de la futura producción inmobiliaria: cerros Alegre, Barón, Los Placeres y Playa Ancha, y la zona de El Almendral. Ya en el segundo periodo (2002-2010) se intensifica la edificación en altura, la que alcanza la mayor superficie de metros cuadrados construidos de las tres microetapas analizadas. Esto se vincula con un modelo de desarrollo de ciudad patrimonial y universitaria, expresado en diversos instrumentos de planificación territorial. Todavía más, estos instrumentos -por acción u omisión- permitieron el incremento de la producción inmobiliaria en los territorios proyectados en la etapa anterior. Finalmente, en el tercer periodo (2011 y 2017), se consolidó la actividad inmobiliaria tanto por el número de proyectos, como por la superficie de metros cuadrados construidos. Estas iniciativas se emplazaron, de manera significativa, en los bordes de las $\mathrm{ZCH}$. Y, junto con ellas, también se infiltraron proyectos de menor envergadura que, adecuándose a las regulaciones, se instalaron en terrenos más pequeños, próximos al centro y a diferentes atractivos patrimoniales.

Los resultados de la investigación expuestos permiten debatir cómo Valparaíso se ha constituido en un escenario privilegiado para la reproducción del capital inmobiliario. Proponemos la categoría de "extractivismo urbano", para complejizar el análisis de los procesos aquí descritos: más allá de las contradicciones que subyacen al modelo de producción de espacio urbano neoliberal, subyace una matriz de (re)producción que intensifica las prácticas de acumulación y despojo. Por lo tanto, la situación descrita a partir de Valparaíso se inscribirse en una red de actividades económicas extractivas, donde los proyectos de edificación exhiben lógicas que se traslapan con las de la minería y el monocultivo extensivo; las mismas que expolian recursos terri- 
toriales estratégicos: la flora y la fauna, el agua y el aire, la tierra y el suelo en diversos territorios de la Región de Valparaíso.

\section{Referencias}

ACOSTA, A. Extractivismo y neoextractivismo: dos caras de la misma maldición. Más allá del desarrollo. En: LANG, M. y MOKRANI, D. (eds.). Más allá del desarrollo. México D. F.: Ediciones Abya Yala, 2012, p. 83-118.

ALARCÓN, M. Renovación del frente portuario de Valparaíso. Oportunidad de rearticulación puerto-ciudad. Revista Cuaderno Urbano, 2009, No8, p. 205-225. https://doi.org/10.30972/crn.88971

ALIMONDA, H. La naturaleza colonizada. Ecología política y minería en América Latina. Buenos Aires: CLACSO, 2011.

ANDUEZA, P. La política de activación patrimonial en Valparaíso. Crítica y propuestas. Encuentro Sociedad Chilena de Políticas Públicas. Santiago: Universidad Adolfo Ibáñez, 2010.

ARAVENA, P. \& SOBARZO, M. Valparaíso. Patrimonio, mercado y gobierno. Concepción: Ediciones Escaparate, 2009.

ARENAS, F., HIDALGO, R. y SANTANA, D. Transformaciones y sostenibilidad del desarrollo urbano. El caso de la zona costera de la región de Valparaíso, Chile. En: ORGANIZACIÓN DE ESTADOS IBEROAMERICANOS PARA LA EDUCACIÓN, LA CIENCIA Y LA CULTURA. Ciudad Autónoma de Buenos Aires: Horizontes y desafíos estratégicos para la ciencia en Iberoamérica. Congreso iberoamericano de ciencia, tecnología, innovación y educación 12,13 y 14 de noviembre de 2014, 2016, p. 309-318.

AZOCAR, N. \& VERGARA-CONSTELA, C. "Plantando condominios". Aproximación general al proceso de gentrificación en La Cruz (Chile) 2002-2014. Scripta Nova. Revista Electrónica de Geografía y Ciencias Sociales, 2019, No617. https://doi.org/10.1344/sn2019.23.21905

BRENNER, N. Tesis sobre urbanización planetaria. Nueva Sociedad, 2013, N²43, p. 38-66.

BONILLA, C., ESCOBAR, H., MAUREIRA, L., MORALES, F. \& PÉREZ, R. El fútbol de barrio en la memoria histórica colectiva del sector de Playa Ancha. Refundando el Club Social y Deportivo Alemania Federal. Valparaíso: Universidad de Playa Ancha, 2018.

CÁCERES, C. Turismo, gentrificación y presión por desplazamiento en los cerros Concepción y Alegre de Valparaíso. Revista INVI, 2019, No97, p. 157-177. http://dx.doi.org/10.4067/S071883582019000300157

CARRAMIÑANA, P. Los imaginarios urbanos y el uso social del espacio barrial. El caso del barrio de Cordillera Central del cerro Cordillera de Valparaíso. Tesis para optar al grado de Licenciado en Sociología y el Título Profesional de Sociólogo. Universidad de Valparaíso, 2016. 
CARROZA, N. \& VALENZUELA, F. Transformaciones en el mercado del trabajo y expresión territorial de las desigualdades sociales. El caso del área metropolitana de Valparaíso. Revista Líder, 2010, N012, p.119-136.

CARROZA, N. \& VALENZUELA, F. Mercados de trabajo y reconfiguración metropolitana: nuevas desigualdades socio-territoriales. El caso del área metropolitana de Valparaíso. En: BAILEY, G., CARROZA, N., ESPINOZA, F. \& TIEMANN, R (eds.). Valparaíso en tránsito. Perspectivas desde una nueva sociología de la ciudad. Valparaíso: El Topo, 2011, p. 44-69.

CARROZA, N., SARAVIA P. y ESCOBAR, S. La producción social del hábitat en el Gran Valparaíso. Discursos críticos, contextos y motivaciones de las experiencias. En: HERNÁNDEZ, A., VERGARA-CONSTELA, C., TUTOR, A. \& SALA, E. (eds.). Neoliberal(urban)ismo. Transformaciones socioterritoriales y luchas populares en Chile, España y México. México D. F.: PUEC-UNAM, 2019, p. 67-75.

CASGRAIN, A. \& JANOSCHKA, M. Gentrificación y resistencia en las ciudades latinoamericanas. El ejemplo de Santiago de Chile. Revista Andamios, 2013, N²2, p. 19-44.

CASTELLS, M. La cuestión urbana. México D. F.: Siglo XXI Editores, 1976.

CLARK, E. The rent gap and the transformation of the built environment. Case studies in Malmo 1860-1985. Geografiska Annaler. Series B, Human Geography, 1988, No2, p. 241-254. https:// /10.1 080/04353684.1988.11879569.

DAHER, A. Neoliberalismo urbano en Chile. Centro de Estudios Públicos, 1991, No43, p. 281-299.

DE MATTOS, C. Santiago de Chile, globalización y expansión metropolitana. Lo que existía sigue existiendo. Revista EURE, 1999, N076, p. 29-56. http://dx.doi.org/10.4067/S0250-71611999007600002

DE MATTOS, C. Modernización capitalista y transformación metropolitana en América Latina. Cinco tendencias constitutivas. En: GERAICES, A., ARROYO, M. \& SILVEIRA, M. (eds.). América Latina. Cidade, campo e turismo. São Paulo: CLACSO, 2006, p. 41-63.

DUPLAT, A. Feminismo y "extractivismo urbano". Notas exploratorias. Nueva Sociedad, 2016, No265, p. 153-163.

FUENTES, L. \& PEZOA, M. Crecimiento urbano reciente del Gran Valparaíso. ¿Hacia una reconfiguración com-fusa? Revista 180, 2017, No40, p. 108-118. http://dx.doi.org/10.32995/rev180.Num-40. (2017).art-328

GARCÍA JEREZ, F. El extractivismo urbano y su giro ecoterritorial. Bitácora urbano territorial, 2019, $\mathrm{N}^{\circ} 29,2$, p. 21-28. https://doi.org/10.15446/bitacora.v29n2.77284

GAUDICHAUD, F., WEBBER, J. y MODONESI, M. Los gobiernos progresistas latinoamericanos del siglo XXI. México D. F.: UNAM, 2019. 
GUDYNAS, E. Diez tesis urgentes sobre el nuevo extractivismo. En: VV. AA. Extractivismo, política y sociedad. Quito: CAAP-CLAES, 2009, p.187-225.

GUERRERO, R. Patrimonio cultural mundial, territorio y construcción de ciudadanía. Construcción y apropiación del patrimonio cultural de la ciudad de Valparaíso-Chile. Scripta Nova. Revista Electrónica de Geografía y Ciencias Sociales, №338, 2012.

HARVEY, D. Los límites del capitalismo y la teoría marxista. México D. F.: Fondo de Cultura Económica, 1990.

HARVEY, D. Espacios del capital. Hacia una geografía crítica. Madrid: Akal, 2017.

HIDALGO, R. Vivienda social y espacio urbano en Santiago de Chile. Una mirada retrospectiva a la acción del Estado en las primeras décadas del siglo XX. Revista EURE, 2002, No83, p. 83-106. http://dx.doi.org/10.4067/S0250-71612002008300006

HIDALGO, R. \& ARENAS, F. Negocios inmobiliarios en el frente litoral del Área Metropolitana de Valparaíso (AMV). Entre la (des)protección del medio natural y la conservación del patrimonio cultural de la UNESCO. Scripta Nova. Revista Electrónica de Geografía y Ciencias Sociales, 2012, No418, p. 1-18.

HIDALGO, R. y BORSDORF, A. Puerto abierto ¿ciudad cerrada? Transformaciones socio-espaciales en la estructura urbana del área metropolitana de Valparaíso. Revista Geográfica de Valparaíso, 2005, No36, p.189-206.

HIDALGO, R., BORSDORF, A. \& SAN MARTÍN, G. Socio-spatial change in the world heritage site Valparaíso. Die Erde Journal of the Geographical Society of Berlin, 2014, No3, p. 228-240. https:// doi.org/10.12854/erde-145-20

HIDALGO, R., PAULSEN, A. \& SANTANA, D. El neoliberalismo subsidiario y la búsqueda de justicia e igualdad en el acceso a la vivienda social. El caso de Santiago de Chile (1970-2015). Revista Andamios, 2016a, No32, p. 57-81.

HIDALGO, R., RODRÍGUEZ, L. \& ALVARADO, V. Arriba del cerro o sobre el humedal. Producción de naturaleza y expansión inmobiliaria en ciudades marinas y fluviales. El caso de Valparaíso y Valdivia, Chile. Diálogo Andino, 2018, N056, p. 87-100. http://dx.doi.org/10.4067/S071926812018000200087.

HIDALGO, R., VOLKER, P. \& RAMÍREZ, N. La ciudad inmobiliaria. Mecanismos institucionales, relaciones de poder y mercantilización del medio natural. El caso del área metropolitana de Valparaíso. Scripta Nova. Revista Electrónica de Geografía y Ciencias Sociales, 2014, № 493.

HIDALGO, R., ALVARADO, V., VOLKER, P., ARENAS, F. \& SALAZAR, A. Ordenamiento costero metropolitano en Chile: de la expectativa de la regulación a la planificación cooptada (1965-2014). 
Cuadernos de Vivienda y Urbanismo, 2015, Vol. 8, №16, p. 206-225. https://doi.org/10.11144/Javeriana.cvu8-16.ocmc

HIDALGO, R., CAMUS, P., PAULSEN, A., OLEA, J. \& ALVARADO, V. Extractivismo inmobiliario, expoliación de los bienes comunes y esquilmación del medio natural. El borde costero en la macrozona central de Chile en las postrimerías del neoliberalismo. En: Die Welt verstehen. Eine geographische Herausforderung. Eine Festschrift der Geographie Innsbruck für Axel Borsdorf. Innsbruck: Die Innsbrucker Geographischen Studien werden herausgegeben vom Innsbrucker Studienkreis für Geographie, 2016b, p. 251-270.

HOCHSTENBACH, C. y BOTERMAN, W. Navigating the field of housing. Housing pathways of young people in Amsterdam. Journal of Housing and Built Environment, 2015, N², p. 257-274. http://10.1007/s10901-014-9405-6

JARAMILLO, S. Hacia una teoría de la renta del suelo urbano. Bogotá: Centro de Estudios sobre Desarrollo Económico, 2010.

KOWARIK, L. Expoliación urbana, luchas sociales y ciudadanía. Retazos de nuestra historia reciente. Revista de Estudios Sociológicos, 1996, N42, p. 729-743.

LEAL, V. \& AGUIRRE, C. Estiba y desestiba. Trabajo y relatos del Valparaíso que fue (1938-1981). Valparaíso: Ediciones Inubicalistas, 2020.

LEFEBVRE, H. La revolución urbana. Santiago: Taller Práxis, 2015.

LÓPEZ-MORALES, E. Gentrificación en Chile. Aportes conceptuales y evidencias para una discusión necesaria. Revista de Geografía Norte Grande, 2013, No56, p. 31-52. http://dx.doi.org/10.4067/ s0718-34022013000300003

LÓPEZ-MORALES, E., GASIC, I. \& MEZA, D. Urbanismo pro empresarial en Chile. Políticas y planificación de la producción residencial en altura en el pericentro del Gran Santiago. Revista INVI, 2012, N076, p. 75-114. http://dx.doi.org/10.4067/S0718-83582012000300003

LÓPEZ-MORALES, E., GASIC, I. \& MEZA, D. Captura desigual de renta de suelo y desplazamiento exclusionario. Indicadores generales del proceso de gentrificación en Santiago de Chile. Cadernos Metrópole, 2014, N032, p. 565-586. http://dx.doi.org/10.1590/2236-9996.2014-3212

LÓPEZ-MORALES, E., SANHUEZA, C., ESPINOZA, S. y ÓRDENES, F. Verticalización inmobiliaria y valorización de renta de suelo por infraestructura pública. Un análisis econométrico del Gran Santiago, 2008-2011. Revista EURE, 2019, N0136, p.113-134. http://dx.doi.org/10.4067/S025071612019000300113

MANSILLA, P. \& FUENZALIDA, M. Procesos de desarrollo urbano-regional y exclusión territorial. Nuevas formas de urbanización en el área metropolitana de Valparaíso. Estudio de caso en ciudad de Curauma. Revista INVI, 2010, No69, p. 103-123. http://10.4067/S0718-83582010000200003 
MARÍN, A., LINK, F. \& VALENZUELA, F. Arriendo en propiedad. Arraigo y vulnerabilidad residencial en el barrio puerto de Valparaíso. Revista INVI, 2017, No90, p. 127-157. http://10.4067/S071883582017000200127

MARX, K. Manuscritos económico-filosóficos 1844. Buenos Aires: Colihue, 2015.

MUGA, E. \& RIVAS, M. Mutaciones y cambios en la estructura urbana del área metropolitana de Valparaíso. En: HIDALGO, R., DE MATTOS, C. \& ARENAS, F. (eds.). Chile. Del país urbano al país metropolitano. Santiago: Serie Geolibros, 2007, p. 201-222.

MINISTERIO DE VIVIENDA Y URBANISMO. Observatorio Habitacional. Estadísticas anuales de edificación aprobada. Santiago de Chile, 2019.

OPAZO, L. Las relaciones entre patrones de asentamiento, formas de poblamiento y dinámicas culturales-habitacionales, como indicadores de impacto de las políticas públicas urbanas en la cohesión territorial. El caso de Valparaíso. Tesis para optar al grado de Magister en Gestión de Proyectos Urbano Regionales. Universidad de Viña del Mar, 2016.

OPILLARD, F. From San Francisco's tech boom 2.0 to Valparaísos's UNESCO world heritage site. En: COLOMB, C. \& NOVY, J. (eds.). Protest and resistance in the tourist city. Nueva York-Londres: Routledge, 2016, p. 129-151.

PANEZ, A. Desarrollo metropolitano del Gran Valparaíso en debate. Divergencias entre discursos y prácticas espaciales de sus actores políticos. Revista Geográfica de Valparaíso, 2015, N051, p.112-132.

PAULSEN, A. Un análisis geográfico de las aproximaciones y distanciamientos entre la teoría del rift metabólico del capitalismo con los planteamientos spatial fix y acumulación por desposesión. Revista Geográfica de Valparaíso, 2019, №56, p. 1-16.

PINO, A. y OJEDA, L. Ciudad y hábitat informal. Las tomas de terreno y la autoconstrucción en las quebradas de Valparaíso. Revista INVI, 2013, N078, p. 109-140. http://10.4067/S071883582013000200004

PINTOS, P. Extractivismo inmobiliario y vulneración de bienes comunes en la cuenca baja del río Luján. En: VÁSQUEZ, A. (ed.). Extractivismo urbano. Debates para una construcción colectiva de las ciudades. Buenos Aires: Fundación Rosa Luxemburgo, 2017, p. 23-39.

PONCE, S., VERGARA-CONSTELA, C. y VALENZUELA, E. Orgullo del puerto. Las tramas invisibles y el sentido vertical de los imaginarios urbanos de Valparaíso a través de Santiago Wanderers. Quinta Normal: Victorino Lainez, 2016.

RAMAS, C. Fetiche y mistificación capitalistas. Madrid: Siglo XXI Editores, 2015.

RODRÍGUEZ, C. La universidad como nuevo eje de desarrollo. El caso de la región de Valparaíso. En: BAILEY, G., CARROZA, N., ESPINOZA, F. \& TIEMANN, R. (eds.). Valparaíso en tránsito. Perspectivas desde una nueva sociología de la ciudad. Valparaíso: El Topo, 2011, p. 138-159. 
RODRÍGUEZ, A. \& SUGRANYES, A. El problema de vivienda de los "con techo". Revista EURE, 2004, No91, p. 53-65. http://dx.doi.org/10.4067/S0250-71612004009100004

ROLNIK, R. La guerra de los lugares. La colonización de la tierra y la vivienda en la era de las finanzas. Santiago: LOM Ediciones, 2017.

SABATINI, F. Reforma de los mercados de suelo en Santiago, Chile. Efectos sobre los precios de la tierra y la segregación residencial. Revista EURE, 2000, N077, p. 49-80. http://dx.doi.org/10.4067/ s0250-71612000007700003

SABATINI, F. La segregación social del espacio en las ciudades de América Latina. Washington D. C.: Banco Interamericano de Desarrollo, 2003.

SABATINI, F. \& CÁCERES, G. Los barrios cerrados y la ruptura del patrón tradicional de segregación en las ciudades latinoamericanas. El caso de Santiago de Chile. En: CÁCERES, G. \& SABATINI, F. (eds.). Barrios Cerrados en Santiago de Chile. Entre la Exclusión y la Integración Residencial. Santiago: Lincoln Institute of Land Policy-Pontificia Universidad Católica de Chile, 2004, p. 9-44.

SANTANA, D. La teoría de lo inmobiliario más allá de la "vieja cuestión urbana": bases para una economía política del espacio social. En: SANTANA, D., ALVARADO, V., e HIDALGO, R. (eds.). Las geografías del neoliberalismo en América del sur. Ensayos descriptivos, críticos y necesarios. Santiago: Serie GeoLibros, 2019, p. 230-262.

SANTOS, M. Por una Geografía nueva. Madrid: Espasa Calpe, 1990.

SLATER, T. Missing Marcuse. On gentrification and displacement. City, 2009, No2, p. 292-311. https://10.1080/13604810902982250

SMITH, N. La nueva frontera urbana. Ciudad revanchista y gentrificación. Madrid: Traficantes de Sueños, 2012.

SVAMPA, M. Consenso de los commodities, giro ecoterritorial y pensamiento crítico en América Latina. OSAL, 2012, N³2, p. 15-38.

SVAMPA, M. Las fronteras del neoextractivismo en América Latina. Conflictos socioambientales, giro ecoterritorial y nuevas dependencias. Bielfeld: Bielfeld University Press, 2019.

TIRONI, M. La nueva pobreza urbana. Precariedad, vivienda y capital social en Santiago de Chile 1985-2001. Santiago: RIL Editores, 2003.

TOPALOV, C. La urbanización capitalista. México D. F.: Edicol, 1979.

TOPALOV, C. Ganancia y rentas urbanas. Elementos teóricos. Madrid: Siglo XXI Editores, 1984.

VALDEBENITO, C. Ni tan cerca ni tan lejos. Trayectoria de la diferenciación social del espacio residencial en la ciudad de Viña del Mar, Chile. Revista Geográfica de Valparaíso, 2017, N054, p. 1-20. 
VARGAS-FRANCIA, D. Valparaíso. La construcción de una imagen urbana de proyección mundial. Valparaíso: RIL Editores, 2018.

VENEGAS, C. El movimiento okupa: resistencia contra el capitalismo. Perspectivas de la Comunicación, 2014, No1, p. 97-131.

VERGARA-CONSTELA, C. ¡Quienes habitan, deciden! La disputa por la planificación urbana en Valparaíso, Chile (2014-2018). En: HERNÁNDEZ, A., VERGARA-CONSTELA, C., TUTOR, A. y SALA, E. (eds.). Neoliberal(urban)ismo. Transformaciones socioterritoriales y luchas populares en Chile, España y México. México D. F.: PUEC-UNAM, 2019, p. 24-31.

VERGARA-CONSTELA, C. y CASELLAS, A. Políticas estatales y transformación urbana ¿Hacia un proceso de gentrificación en Valparaíso Chile? Revista EURE, 2016, N0126, p. 123-144. http://dx. doi.org/10.4067/S0250-71612016000200006

VIALE, E. (2017). El extractivismo urbano. En: VÁSQUEZ, A. (ed.). Extractivismo urbano. Debates para una construcción colectiva de las ciudades. Buenos Aires: Fundación Rosa Luxemburgo, 2017, p. 15-24. 
